\title{
GÜÍMAR AND LA OROTAVA MEGA-LANDSLIDES (TENERIFE) AND TSUNAMIS DEPOSITS IN CANARY ISLANDS
}

\author{
Ferrer, M. ${ }^{a}$, De Vallejo, L.G. ${ }^{b}$, Seisdedos, J. ${ }^{c}$, Coello, J.J. ${ }^{d}$, García, J.C. ${ }^{a}$, Hernández, L.E. ${ }^{\text {, }}$, Casillas, \\ R. ${ }^{f}$, Martín, C. ${ }^{f}$, Rodríguez, J.A. ${ }^{f}$, Madeira, J. ${ }^{g}$, Andrade, C. ${ }^{g}$, Freitas, M.C. ${ }^{g}$, Lomoschitz, A. ${ }^{h}$, \\ Yepes, J. ${ }^{\mathrm{h}}$, Meco, J. ${ }^{\mathrm{h}}$, Betancort, J.F. ${ }^{\mathrm{h}}$
}

\author{
a Geological Survey of Spain, Ríos Rosas 23, 28003 Madrid, Spain \\ b Complutense University of Madrid, Madrid, Spain \\ c Prospección y Geotecnia, S.L. (PyG), Madrid, Spain \\ d Consejo Insular de Tenerife, Calle Leoncio Rguez., 7, 38003 S/C de Tenerife, Spain \\ e Government of the Canary Islands, Spain \\ f University of la Laguna, Tenerife, Spain \\ g University of Lisbon, Lisbon, Portugal \\ h University of Las Palmas de Gran Canaria, Las Palmas (The Canary Island), E-35017 Las Palmas, Spain
}

\begin{abstract}
More than 20 mega-landslides have been described in the Canary Islands affecting the flanks of the volcanic edifices. Güimar and La Orotava landslides, in Tenerife, are two exceptional cases due to their huge dimensions and outstanding geomorphological features. The estimated volume of these landslides exceed tens of cubic $\mathrm{km}$. Tsunami deposits have been also identified in some of the islands of the archipelago probably associated to the large landslides of the islands flanks. An investigation has been carried out to explain the causes of these large instability processes and their failure mechanisms. One of the main aspects investigated was the geomechanical characteristics of the volcanic rock masses, specially the hyaloclastite rocks forming the substratum underlying the emerged volcanic building. The low strength and high deformability properties of these rocks have played a fundamental role on the stability of the island flanks. The results have shown the gravitational origin of these instability processes as the main failure mechanism. Volcanic eruptions or large earthquakes could be contributing factors to the instability, but according with the data obtained in Guimar and La Orotava cases they are not necessary as triggering factors. As a result of the field work carried out in the frame of the project, three large tsunami deposits have been identified in the islands of Lanzarote, Tenerife and Gran Canaria attributed to mega-landslides, possibly related to Guimar and La Orotava. A summary of their main features is described.
\end{abstract}

